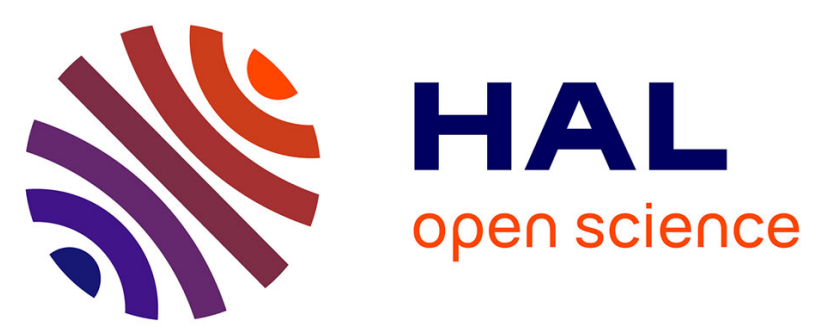

\title{
Antiaggregation potential of berry fractions against pairs of Streptococcus mutans with Fusobacterium nucleatum or Actinomyces naeslundii
}

Kaisu Ristiina Riihinen, Anu Ryynanen, Marko Toivanen, Eija Kononen, Riitta Torronen, Carina Tikkanen-Kaukanen

\section{To cite this version:}

Kaisu Ristiina Riihinen, Anu Ryynanen, Marko Toivanen, Eija Kononen, Riitta Torronen, et al.. Antiaggregation potential of berry fractions against pairs of Streptococcus mutans with Fusobacterium nucleatum or Actinomyces naeslundii. Phytotherapy Research, 2010, 25 (1), pp.81. 10.1002/ptr.3228 . hal-00599831

\section{HAL Id: hal-00599831 \\ https://hal.science/hal-00599831}

Submitted on 11 Jun 2011

HAL is a multi-disciplinary open access archive for the deposit and dissemination of scientific research documents, whether they are published or not. The documents may come from teaching and research institutions in France or abroad, or from public or private research centers.
L'archive ouverte pluridisciplinaire $\mathbf{H A L}$, est destinée au dépôt et à la diffusion de documents scientifiques de niveau recherche, publiés ou non, émanant des établissements d'enseignement et de recherche français ou étrangers, des laboratoires publics ou privés. 


\section{Antiaggregation potential of berry fractions against pairs of Streptococcus mutans with Fusobacterium nucleatum or Actinomyces naeslundii}

\begin{tabular}{|c|c|}
\hline Journal: & Phytotherapy Research \\
\hline Manuscript ID: & PTR-10-0048.R1 \\
\hline Wiley - Manuscript type: & Full Paper \\
\hline $\begin{array}{r}\text { Date Submitted by the } \\
\text { Author: }\end{array}$ & 16-Apr-2010 \\
\hline Complete List of Authors: & $\begin{array}{l}\text { Riihinen, Kaisu; University of Eastern Finland, Department of } \\
\text { Biosciences; University of Illinois at Chicago, College of Pharmacy } \\
\text { Ryynanen, Anu; University of Eastern Finland, Clinical Nutrition } \\
\text { Toivanen, Marko; University of Eastern Finland, School of Pharmacy } \\
\text { Kononen, Eija; University of Turku, Institute of Dentistry } \\
\text { Torronen, Riitta; University of Eastern Finland, Clinical Nutrition } \\
\text { Tikkanen-Kaukanen, Carina; University of Eastern Finland, Institute } \\
\text { of Public Health and Clinical Nutrition }\end{array}$ \\
\hline Keyword: & polyphenols, dental, antiadhesion, flavonoids \\
\hline
\end{tabular}

\section{s ScholarONE" \\ Manuscript Central}



6

\title{
Antiaggregation potential of berry fractions
}

\author{
against pairs of Streptococcus mutans with
}

Fusobacterium nucleatum or Actinomyces

\section{naeslundii}

Kaisu Riihinen ${ }^{a}$, Anu Ryynänen ${ }^{b}$, Marko Toivanen $^{c}$, Eija Könönen $^{d, e}$, Riitta Törrönen ${ }^{b}$ and Carina Tikkanen-Kaukanen ${ }^{c, f}$

${ }^{\mathrm{a}}$ Department of Biosciences, ${ }^{\mathrm{b}}$ Institute of Public Health and Clinical Nutrition, Department 8 of Clinical Nutrition, Food and Health Research Centre, ${ }^{\mathrm{c} D e p a r t m e n t}$ of Pharmaceutical Chemistry, University of Eastern Finland, P.O.Box 1627, FI-70211 Kuopio, Finland, ${ }^{\mathrm{d}}$ Department of Infectious Disease Surveillance and Control, National Institute for Health and Welfare (THL), P.O.Box 30, FI-00271 Helsinki and ${ }^{\mathrm{e}}$ Institute of Dentistry, University of Turku, FI-20520 Turku, Finland, ${ }^{\mathrm{f}}$ Institute of Public Health and Clinical Nutrition, Department of Public Health, University of Eastern Finland, P.O.Box 1627, FI-70211 Kuopio, Finland

15 Short title: Berry fractions with antiaggregation potential

16 *Corresponding author. Tel.: +1-708-209 9091; fax: +358-17-163322

7 E-mail address: Kaisu.Riihinen@uef.fi 


\section{ABSTRACT}

19 Coaggregation is an interspecies adhesion process, which is essential to the development of

20 dental plaque. Here we studied in vitro the composition of the soluble solids in the berry 21 juice molecular size fractions [ $<10 \mathrm{kDa}, \mathrm{FI}$; 10-100 kDa, FII; $>100 \mathrm{kDa}, \mathrm{FIII}]$ derived from

22 apple, bilberry, blackcurrant, cloudberry, crowberry, and lingonberry and their ability to 23 inhibit and reverse coaggregation of the pairs of common species in dental plaque:

24 Streptococcus mutans with Fusobacterium nucleatum or Actinomyces naeslundii. Inhibitory 25 and reversal activity was found in the molecular size fractions FII and FIII of bilberry, 26 blackcurrant, crowberry, and lingonberry. The active fractions contained higher amounts of 27 polyphenols $(5-12 \%$ of soluble solids) than those without activity ( $<2 \%$ of soluble solids). 28 Proanthocyanidins dominated in the active lingonberry juice fractions FII and FIII and also 29 small amounts of anthocyanins were detected. Anthocyanins, proanthocyanidins, and 30 flavonol glycosides were prevalent in FII and FIII fractions of bilberry, blackcurrant, and 31 crowberry juices. Comparable amounts of sugars and titratable acids were present in the 32 latter three berry juice fractions of different size. The results indicate that the high 33 molecular size fractions of lingonberry, bilberry, blackcurrant, and crowberry juices have 34 antiaggregation potential on common oral bacteria, the potential being associated to their 35 polyphenolic content.

36 Keywords: berries; dental biofilms; antiadhesion; coaggregation; antiaggregation; 37 polyphenols 


\section{$38 \quad$ INTRODUCTION}

39 Streptococcus, Actinomyces, and Fusobacterium are among the major bacterial genera,

40 which colonize the oral cavity early in life (Könönen, 2000) and form crucial constituents of

41 dental plaque, i.e., dental biofilms accumulating on non-shedding tooth surfaces

42 (Kolenbrander et al., 2006; Rosan and Lamont, 2000). Dental biofilms play a crucial role in

43 the pathogenesis of the two most common oral infections, caries and periodontal diseases,

44 where intergeneric coaggregation contributes to the development of cariogenic and

45 periodontopathogenic communities (Kolenbrander et al., 2006; Sbordone et al., 2003). The

46 first step in the formation of dental plaque is the adhesion of early colonizers (streptococci

47 and Actinomyces) to the pellicle-coated tooth surface, while Fusobacterium nucleatum acts

48 as a bridge between early and late colonizers, coaggregating with most oral bacteria

49 examined (Al-Ahmad et al., 2007; Kolenbrander et al., 2006). Coaggregation is a further

50 adhesion process by which two genetically distinct bacteria become attached to one another

51 via specific molecules present in the biofilms. The basics of coaggregation have been

52 examined in vitro with the simple method of mixing bacterial suspensions together

53 (Kolenbrander et al., 2006).

54 While antimicrobial agents inhibit the survival and growth of bacteria, antiadhesion and 55 antiaggregation agents affect the formation of bacterial biofilms on oral surfaces. According to Weiss et al. (2002), the American cranberry (Vaccinium macrocarpon) constituents are

57 able to inhibit and reverse the coaggregation of dental plaque bacteria (antiaggregation). In

58 this context, information on other berries is still limited. Also, cranberry has been 59 demonstrated to inhibit oral bacterial adhesion in artificial biofilms (Steinberg et al., 2005;

60 Yamanaka et al., 2004; 2007). Polyphenols are considered to be involved in nonspecific

61 antiadhesion effects against oral bacteria (Duarte et al., 2006; Ferrazzano et al., 2009; 
62 Yamanaka et al., 2007). The most predominant polyphenols in berries are anthocyanins

63 (anthocyanidin glycosides) (Määttä-Riihinen et al., 2004a; 2004b; Määttä et al., 2001),

64 which are seen as light red to bluish black pigments. Flavonol glycosides and

65 proanthocyanidins are other abundant polyphenols in berries (Hellström et al., 2009;

66 Määttä-Riihinen et al., 2004b). Recently, we reported that juice fractions of different

67 molecular size prepared from bilberry (Vaccinium myrtillus), blackcurrant (Ribes nigrum),

68 cranberry (Vaccinium oxycoccus), crowberry (Empetrum nigrum \& hermaphroditum), and

69 lingonberry (Vaccinium vitis-idaea) exhibit antiadhesion activity against a Gram-negative

70 human pathogen Neisseria meningitidis (Toivanen et al., 2009). We have also shown

71 binding or inhibitory activities of molecular size fractions prepared from Vaccinium berries

72 and crowberry against different pathogenic streptococcal strains of human or animal origin

73 (Toivanen et al., 2010).

74 The aim of the present study was to investigate in vitro the inhibition and reversal ability

75 of apple, bilberry, blackcurrant, cloudberry (Rubus chamaemorus), crowberry, and

76 lingonberry juice fractions against two pairs of oral bacterial species, namely, Streptococcus

77 mutans with either F. nucleatum or Actinomyces naeslundii. In addition, the amount of

78 titratable acids, sugars, proanthocyanidins, anthocyanins, and flavonol glycosides in the

79 berry juice fractions was measured. 


\section{MATERIALS AND METHODS}

81 Juice fractions. Juice concentrates of apple (mix of cultivars) $\left(70^{\circ} \mathrm{Brix}\right.$, content of soluble solids g/100 g of solution) and blackcurrant $\left(65^{\circ}\right.$ Brix $)$ were obtained from VIP-Juicemaker Ltd (Kuopio, Finland). Bilberry, lingonberry, and crowberry (berry juice concentrates $\left(65^{\circ}\right.$ Brix $)$ and cloudberries were purchased from Kiantama Ltd (Suomussalmi, Finland). Berry juices were stored at $-20^{\circ} \mathrm{C}$ until used. The juices were fractionated into three different fractions, $<10 \mathrm{kDa}$ fraction (FI), 10-100 kDa fraction (FII), and $>100 \mathrm{kDa}$ fraction (FIII), through a molecular sieve by centrifugal filtering, as previously described (Toivanen et al., 2009; 2010). The soluble solids (SS) in the fractions were analyzed as ${ }^{\circ}$ Brix values (SS g/100 g) using a digital refractometer (ATAGO PR-32, Tokyo, Japan) and diluted to the fixed SS content of $12 \mathrm{~g} / 100 \mathrm{~g}$, except for the cloudberry juice fractions, which were analyzed as such.

Analyses of titratable acids and sugars. Titratable acids and sugars were analyzed based on the methods developed for various foods (Anon., 2000). Titratable acids were measured from the juice fractions diluted in water by titrating with alkaline solution to their potentiometric endpoint. The amounts of titratable acids were calculated by using the equivalent weights of the major acids in berries (malic acid in apple, cloudberry, and crowberry, and citric acid in bilberry, blackcurrant, and lingonberry). Sucrose was inverted with acid hydrolysis prior to the analysis of reducing sugars with the Schoorl method (Anon., 2000). Reducing sugars were determined by using stabilized alkaline solution of a copper salt (two Fehling's solutions). In the reaction, the amount of reduced copper is proportional to the amount of reducing sugars in the sample. The determination was continued by immediate titration with standard sodium thiosulphate solution until the end 
104 point. Water was used as blank for the samples. The sugar content was read from a

105

106

107

108

109

110

111

112

113

114

115

116

117

118

119

120

121

122

123

124

125

126

127

128

conversion table based on the titer difference of the sample from the blank.

Analysis of proanthocyanidins. Proanthocyanidin contents in the fractionated juices was estimated by a spectrophotometric procedure (Rohr et al., 2000), which was modified as described by Toivanen et al. (2009). Briefly, juice fractions were diluted in acidified methanol $(0.6 \mathrm{M} \mathrm{HCl})$ and the absorbance values of the samples were measured at $520 \mathrm{~nm}$ with a UV-visible spectrophotometer (Shimadzu UV-1650PC; Kyoto, Japan) before and after incubation at $+70^{\circ} \mathrm{C}$ (Memmert ULE 500 oven, Schwabach, Germany) for $3 \mathrm{~h}$. The absorbance differences of incubated and nonincubated samples were used for semiquantification of proanthocyanidins as released anthocyanidins. The calibration curves of proanthocyanidins were constructed by using depolymerized lingonberry dimer and trimer isolate with purity of $80 \%$ (Määttä-Riihinen et al., 2005). The range of the calibration curve corresponded to $0.6-30 \%$ of proanthocyanidins of SS in the juice samples.

Analyses of anthocyanins and flavonol glycosides. In order to analyze anthocyanins and flavonol glycosides, the fractions were first diluted with methanol and acidified with concentrated $\mathrm{HCl}$ to $0.6 \mathrm{M}$ and then filtered through a $0.45-\mu \mathrm{m}$ syringe filter (Pall Life Sciences, Ann Arbor, MI) to the vials. High-performance liquid chromatography with diode array detection (HPLC-DAD) apparatus consisted of a Hewlett-Packard (HP) instrument with a 1100 series quaternary pump, an autosampler, and a diode array detector linked to an HP-ChemStation data handling system (Waldbronn Analytical Division, Germany). HPLC separation was achieved on a $(150$ x $4.6 \mathrm{~mm}$ i.d., $5 \mu \mathrm{m})$ Phenomenex Gemini reversed phased (RP) column (RP-18, Merck, Darmstadt, Germany) protected with a guard column of the same material $(4 \times 3 \mathrm{~mm})$. The gradient program based on acetonitrile and methanol (ACN:MeOH, 85:15, v/v) as the organic phase and $8.5 \%$ formic acid as the water phase was modified from the procedure of Lätti et al. (2008). The gradual increase of the ACN-MeOH 
at flow rate of $1 \mathrm{ml} / \mathrm{min}$ was arranged as follows: 4-10\% (0-2 $\mathrm{min}), 10 \%$ (2-20 $\mathrm{min}), 10-$ $15 \%$ (20-35 $\mathrm{min}), 15-35 \%$ (35-40 $\mathrm{min}), 35-80 \%$ (40-50 $\mathrm{min}$ ), $80 \%$ (50-52 $\mathrm{min}$ ), return to initial conditions in $8 \mathrm{~min}$, and re-equilibration of the column for $10 \mathrm{~min}$. Anthocyanins (at $520 \mathrm{~nm}$ ) and flavonol glycosides (at $360 \mathrm{~nm}$ ) were identified based on our earlier HPLCDAD identification (Määttä-Riihinen et al., 2004a; 2004b; Määttä et al., 2001). The response factors for quantification of anthocyanins and flavonol glycosides were determined from freshly prepared solutions of cyanidin-3-glucoside and quercetin-3-glucoside in the concentration ranges $1.8-386 \mathrm{mg} / \mathrm{l}$ and $2-250 \mathrm{mg} / \mathrm{l}$, respectively. Flavonol glycoside same solvent composition as used for the samples, since $\mathrm{pH}$ and water content affect the absorption coefficient of anthocyanins.

Bacterial strains. Five clinical strains were selected, including Gram-positive $S$. mutans

IH 113728, A. naeslundii AHP 28639 and AHP 28651, and Gram-negative F. nucleatum AHN 23952 and AHN 23937. The strains were grown in Brain Heart Infusion (BHI, LabM,

144 England) broth with $0.5 \%$ yeast extract (Difco) under anaerobic conditions at $37^{\circ} \mathrm{C}$. The bacterial cells were harvested and washed with Dulbecco's phosphate-buffered saline (DPBS) (10X stock solution, ECM4053, Eurolone) containing calcium and magnesium. The washed cells were then either suspended in coaggregation buffer D-PBS to an optical 148 density of 1.5 at $400 \mathrm{~nm}$ (UV-Vis Spectrophotometer, GENESYS 10 Series, Thermo 149 Electron Corporation) for the coaggregation assay or stored at $-20^{\circ} \mathrm{C}$ in $50 \%$ glycerol 150 (99.5\%, analytical grade, Normpur). The suspended cells were stored at $4^{\circ} \mathrm{C}$ for the test period of two weeks.

Coaggregation and antiaggregation assay. The inhibition and reversal activities of the 
154 modification of the turbidimetric assay developed by McIntire et al. (Kolenbrander, 1995;

155 McIntire et al., 1982). The coaggregating bacteria used in the assays were $S$. mutans with

156 either A. naeslundii (two strains) or F. nucleatum (two strains). In order to obtain four

157 parallel results, the antiaggregation assays were carried out in two runs. Berry juice

158 fractions were diluted in D-PBS to the concentrations of 12 and $48 \mathrm{mg} / \mathrm{g}$. Coaggregation

159 assays, inhibition and reversal of bacterial aggregates, and background measurements were

160 run simultaneously. In the inhibition assays, a $25 \mu \mathrm{l}$ aliquot of each berry juice fraction was

161 mixed vigorously for $10 \mathrm{~s}$ with $25 \mu 1$ of D-PBST (D-PBS with $0.05 \%$ (v/v) Tween20) and

162 with $25 \mu 1$ of the cell suspension of $S$. mutans and A. naeslundii or F. nucleatum. In the

163 reversal test, $25 \mu 1$ of the $S$. mutans cell suspension, $25 \mu 1$ of the A. naeslundii or $F$.

164 nucleatum cell suspension, and $25 \mu \mathrm{l}$ of D-PBST were vigorously mixed for $10 \mathrm{~s}$. To allow

165 the formation of stable bacterial aggregates or bacterium-berry coupling, the mixtures were

166 then agitated gently (100 revolutions per minute) in an orbital shaker (Orbital Shaker, Stuart

167 Scientific, United Kingdom) for $30 \mathrm{~min}$. Then the other bacterial pair ( $25 \mu 1$ of the cell

168 suspension) was added to the inhibition test mixtures and berry juice fraction $(25 \mu 1)$ was

169 added to the reversal test mixtures. For background measurements, two different blanks

170 were made. The blanks were prepared by mixing $25 \mu 1$ of each bacterial cell suspension

171 with $50 \mu \mathrm{l}$ of D-PBST and $25 \mu \mathrm{l}$ of the berry fraction as well as by mixing $25 \mu \mathrm{l}$ of each cell

172 suspension with $75 \mu \mathrm{l}$ of D-PBST. The coaggregation score for each bacterial pair was

173 measured from the mixture containing $25 \mu 1$ of the both cell suspensions and $50 \mu 1$ of D-

174 PBST. All the prepared samples and blanks were mixed vigorously, agitated gently for 30

175 min, as described above, and then $200 \mu \mathrm{l}$ of D-PBST was added. The mixtures were then

176 centrifuged at $200 \mathrm{rpm}$ (Eppendorf centrifuge 5415D, Hamburg, Germany) for 10 min to

177 pack down the aggregates. The top part of the supernatant was transferred to a flat-bottomed 
178 microtiter well. The turbidity was measured at $630 \mathrm{~nm}$ by using a microtiter plate reader 179 (Victor2, 1420 Multilabel counter, Wallac, PerkinElmer LifeSciences, Boston, USA).

180 The coaggregation percent was calculated as follows:

182 Coaggregation $\%=\frac{\left(A_{1}+A_{2}\right)-\left(A_{1+2}\right)}{\left(A_{1}+A_{2}\right)} * 100$

183

184 where $A_{1}$ and $A_{2}$ present absorptions of the bacterial cell suspensions and $A_{1+2}$ presents 185 absorption of the coaggregation mixtures. The inhibition and the reversal activity induced 186 by the juice fractions $(\mathrm{F})$ was expressed as percents and calculated as follows:

$$
\text { Inhibition } / \text { reversal } \%=\frac{\text { Coaggregation } \%-\text { CoaggregationF } \%}{\text { Coaggregation } \%} * 100
$$


190

191

192

193

194

195

196

197

198

199

200

201

202

203

204

205

206

207

208

209

210

211

212

213

214

\section{ReSUlts}

Composition of the juice fractions. The contents of proanthocyanidins and anthocyanins in the juice fractions varied between different berry species (Table 1). The low molecular size fractions $(<10 \mathrm{kDa}$ in $\mathrm{FI})$ and all the three fractions of apple and cloudberry displayed low amounts of proanthocyanidins and no anthocyanins. The anthocyanin concentration was high in bilberry FII and FIII (3.99 \% and 5.21\% of SS, respectively) and in crowberry FII and FIII (2.80\% and $5.18 \%$, respectively). The proanthocyanidin concentration was high in blackcurrant FII and FIII (8.5\% and 6.2\%, respectively), in crowberry FII and FIII (5.8\% and $6.3 \%$, respectively), and in lingonberry FII and FIII (5.8\% and 4.7\%, respectively). Although the anthocyanin contents were lower in fractions FI, the chromatographic profiles of anthocyanins in the three fractions of the bilberry, blackcurrant, crowberry, and lingonberry juices were identical in RP-HPLC-DAD analysis, as shown for crowberry in Figure 1. Flavonol glycosides were distributed mainly in fractions FII and FIII and major contents were $0.14 \%$ of SS in bilberry FIII, $0.09 \%$ of SS in blackcurrant FII, $0.05 \%$ of SS in blackcurrant FIII, and $0.07 \%$ of SS in crowberry FIII (Table 1). Titratable acids and sugars were detected in comparable amounts in all the three fractions (Table 1).

\section{Coaggregation and antiaggregation assays. The degree of coaggregation was relatively} low, being equal between $S$. mutans IH 113728 and the two strains of A. naeslundii (AHP 28639 and AHP 28651) and between S. mutans IH 113728 and the two strains of $F$. nucleatum (AHN 23952 and AHN 23937) (Table 2). Inhibition and reversal activities less than $50 \%$ were ignored, as proposed by McIntire et al. (1982). All positive scores for inhibition and reversal (antiaggregation) activities displayed low standard deviations and were reproducible in the four experiments. The reversal and inhibitory activity was found in FII and FIII of bilberry, blackcurrant, crowberry, and lingonberry juices (Table 2). The antiaggregation activity was detected in all eight bacterial pairs with the fraction FII of 
215 bilberry, crowberry, and lingonberry juices. In addition, the crowberry juice fraction FIII

216 had antiaggregation activity to seven of the eight studied pairs. Of the blackcurrant juice

217 fractions, FIII was the most active but the effect was limited to the four bacterial pairs of $S$.

218 mutans and $A$. naeslundii. The blackcurrant FII fraction had effect only to one of the studied 219 eight bacterial pairs. The fractions FIII of bilberry juice and lingonberry juice showed 220 activity to three and one of the eight bacterial pairs, respectively. The antiaggregation was 221 mainly achieved with the berry concentration of $48 \mathrm{mg} / \mathrm{g}$ of SS. The crowberry juice 222 fraction FIII with the concentration of $12 \mathrm{mg} / \mathrm{g}$ of SS gave reversal activity to two of the 223 bacterial pairs and that of blackcurrant induced aggregation inhibition of one bacterial pair.

224 The inhibitory and reversal activity of $100 \%$ was detected in the FII fraction of bilberry 225 juice with the concentration of $48 \mathrm{mg} / \mathrm{g}$ of SS. The fractions of apple and cloudberry juices 226 exhibited no antiaggregation activity. 
227

228

229

230

231

232

233

234

235

236

237

238

239

240

241

242

243

244

245

246

247

248

249

\section{DISCUSSION}

The fractions of bilberry, blackcurrant, crowberry, and lingonberry demonstrated antiaggregation activity against the oral bacterial pairs examined. As shown in the present study and previous studies using spectrophotometric and chromatographic or NMR analyses (Toivanen et al., 2009, 2010), these berries possess high proportions of polyphenols. In the fractions without antiaggregation activity, the polyphenol content was very low or polyphenols were not detected.

Plant-derived substances can affect the formation of bacterial aggregates either by inhibition of their formation and by reversal of formed units, which mechanisms may be applied in the control of plaque-related diseases (Allaker et al., 2009). In the present antiaggregation study, the berry fractions were selected based on our recent results achieved with berry juice fractions against pathogens, including Gram-positive Streptococcus strains, S. pneumonia, S. agalactiae, and S. suis, and a Gram-negative N. meningitidis (Toivanen et al., 2009; 2010). In the present study, S. mutans was selected for coaggregation experiments, since it has been considered as one of the key organisms involved in caries (Kleinberg, 2002), while A. naeslundii and F. nucleatum are important species in the maturation process of dental biofilms (Al-Ahmad et al., 2007). In general, oral streptococci are prominent early colonizers on tooth enamel and they form coaggregates with other early colonizers, such as Actinomyces. However, coaggregation scores between $S$. mutans and A. naeslundii have been found to be rather weak (Cisar et al., 1979; Crowley et al., 1987). Thus, the low coaggregation score found for the pairs of $S$. mutans with the two strains of $A$. naeslundii in the present study was expected. Furthermore, $S$. mutans coaggregated with $F$. nucleatum strains with a low score. The low coaggregation scores were taken into 
consideration in calculations so that inhibition and reversal activities less than $50 \%$ were not considered significant.

252 It is notable that the antiaggregation activity may not be connected to a certain group of 253 polyphenols. As shown in Table 1, the fractions FII and FIII of bilberry juice contained a 254 relatively high amount of anthocyanins but a low amount of proanthocyanidins, while high 255 amounts of both anthocyanins and proanthocyanidins were found in the fractions FII and 256 FIII of crowberry juice. In contrast, in the fractions FII and FIII of lingonberry and 257 blackcurrant juices, the anthocyanin concentration was low compared to the 258 proanthocyanidin concentration. Flavonol glycosides were found predominantly in active 259 fractions, which may have an impact on antiaggregation activity, however, their amount 260 was lower compared to major proanthocyanidins and anthocyanins. We have recently 261 demonstrated that polyphenol macromolecular complexes with proanthocyanidins and 262 polyhydroxyflavonoids are present in the active berry juice fractions FII and FIII, while 263 these complexes are absent in the inactive FI and in weakly effective lingonberry FIII 264 fractions (Toivanen et al., 2009).

265 According to our recent nuclear magnetic resonance (NMR) analysis (Toivanen et al., 266 2010), high molecular size fractions contain low molecular weight sugars (mainly glucose) 267 and benzoic acid and high molecular weight polyphenols. In the present study, acids and 268 sugars were equally found both in active and in inactive fractions (Table 1), indicating that 269 they are not the major promoters of the antiaggregation properties. This observation is in 270 agreement with earlier studies (Johnson-White et al., 2006; Steinberg et al., 2005). Our 271 finding on identical chromatographic profiles of anthocyanins (Figure 1) in the fractions FI, 272 FII, and FIII of bilberry, blackcurrant, and crowberry juices indicates that the three fractions 273 contained similar anthocyanin molecules. Although the antiaggregation activity seems to be 
274 associated with polyphenols, it is not due to the specific anthocyanin structures in the 275 studied bilberry, blackcurrant or crowberry juice fractions.

276 Among berries, there are two different types of proanthocyanidins: A-type (rare) and B277 type (common). The rare A-types dominate in the Finnish Vaccinium berries (Määttä278 Riihinen et al., 2005). The type of proanthocyanidin can influence the antiaggregation 279 ability (Foo et al., 2000). This concerns especially the high molecular size fraction FII of 280 lingonberry juice but also its weakly effective fraction FIII. In lingonberry and blackcurrant 281 juice fractions, the antiaggregation activity may result from the high content of 282 proanthocyanidins as well.

283 It has been demonstrated that the polyphenol fraction $(0.25 \mathrm{mg} / \mathrm{ml}$ of which $62 \%$ were 284 polyphenols) of American cranberry is able to inhibit the biofilm formation of two 285 periodontitis-associated anaerobes, Porphyromonas gingivalis and F. nucleatum (Yamanaka 286 et al., 2007). In another study, cranberry proanthocyanidins $(0.500 \mathrm{mg} / \mathrm{ml})$ and flavonols $287(0.125 \mathrm{mg} / \mathrm{ml})$, alone or in combination, reduced the formation and accumulation of $S$. 288 mutans biofilms (Duarte et al., 2006). In the present study, 0.6-1.4 mg/g of polyphenols in 289 bilberry, blackcurrant, crowberry, and lingonberry juice fractions displayed inhibition 290 and/or reversal activity against the studied coaggregates. The dilutions of the juice fractions 291 used in our antiaggregation assay represented the concentrations present in a drinkable 292 juice.

293 Berry juices can have a high content of fructose, glucose, citric acid, and malic acid 294 (Viljakainen et al., 2002). Therefore, a drinkable berry juice without further processing is 295 unsuitable for oral hygiene purposes. In the present study, considerable amounts of sugars 296 and titratable acids were present in all the three fractions examined. Low molecular weight 
sugars are fermentable by acid-producing dental bacteria in plaque, which may increase the risk of dental caries. Moreover, the low $\mathrm{pH}$ value and titratable acidity are the major chemical risk factors for dental erosion (Lussi and Jaeggi, 2008). Therefore, for clinical studies or for possible clinical applications, antiaggregative berry polyphenols should be isolated from the active fractions, as described for the high molecular weight non-dialyzable material from cranberry juice concentrate (Weiss et al., 2004). In the case of polyphenolic beverages, such as cocoa bean husk extract, red wine, cistus, and black tea, which have also shown their potential in prevention of biofilm-induced diseases in the oral cavity, no further processing is needed (Matsumoto et al., 2004; Hannig et al., 2009). There is preliminary in vivo evidence that daily usage of a mouthwash containing cranberry constituents or cacao bean husk can reduce mutans streptococcal counts in the mouth (Matsumoto et al., 2004;

Weiss et al., 2004). It has recently been reported that oral rinses with red wine, cistus tea, and black tea can reduce the total count of adherent bacteria (Hannig et al., 2009).

Our in vitro results suggest that polyphenol constituents in the high molecular size fractions of bilberry, blackcurrant, crowberry, and lingonberry juices may affect the coaggregation capabilities of oral bacteria. Anthocyanins, proanthocyanidins, and flavonol glycosides may be responsible for the observed antiaggregation activity. The susceptibility of oral biofilms to antimicrobial and antiaggregation agents is limited due to the properties of the microbial community (Sbordone et al., 2003). Therefore, the results of the present coaggregation study may not be directly extrapolated as an evidence of the inhibitory effect of the berry components against dental biofilms. Although berry polyphenols have shown their antiaggregation potential, sugars and acids should be eliminated from berry material to get it more suitable for oral hygiene purposes. In order to evaluate the effect of various 
320 berry components on oral pathogens, characterization of the antiaggregative molecules and 321 in vivo studies will be needed. 
1

2

3

4

5

6

7

8

9

10

11

12 
328

329

330

331

332

333

334

335

336

337

338

339

340

341

342

343

344

345

346

347

348

349

350

351

\section{REFERENCES}

Al-Ahmad A, Wunder A, Auschill TA, Follo M, Braun G, Hellwig E, Arweiler NB. 2007.

The in vivo dynamics of Streptococcus spp., Actinomyces naeslundii,

Fusobacterium nucleatum and Veillonella spp. in dental plaque biofilm as analysed by five-colour multiplex fluorescence in situ hybridization. J Med Microbiol 56:681-687.

Allaker RP, Douglas CW. 2009. Novel anti-microbial therapies for dental plaque-related diseases. Int J Antimicrob Agents 33:8-13.

Anon. 2000. Approved methods of the American Association of Cereal Chemists. St. Paul: ACCC: Minneapolis.

Beachey EH. 1981. Bacterial adherence: adhesin-receptor interactions mediating the attachment of bacteria to mucosal surface. J Infect Dis 143:325-345.

Cisar JO, Kolenbrander PE, McIntire FC. 1979. Specificity of coaggregation reactions between human oral streptococci and strains of Actinomyces viscosus or Actinomyces naeslundii. Infect Immun 24:742-752.

Crowley PJ, Fischlschweiger W, Coleman SE, Bleiweis AS. 1987. Intergeneric bacterial coaggregations involving mutans streptococci and oral actinomyces. Infect Immun 55:2695-2700.

Duarte S, Gregoire S, Singh AP, Vorsa N, Schaich K, Bowen WH, Koo H. 2006. Inhibitory effects of cranberry polyphenols on formation and acidogenicity of Streptococcus mutans biofilms. FEMS Microbiol Lett 257:50-56.

Ferrazzano GF, Amato I, Ingenito A, De Natale A, Pollio A. 2009. Anti-cariogenic effects of polyphenols from plant stimulant beverages (cocoa, coffee, tea). Fitoterapia 80:255-262. 
352 Foo LY, Lu Y, Howell AB, Vorsa N. 2000. A-Type proanthocyanidin trimers from

353

354

355

356

357

358

359

360

361

362

363

364

365

366

367

368

369

370

371

372

373

374

375

376 cranberry that inhibit adherence of uropathogenic P-fimbriated Escherichia coli. $J$ Nat Prod 63:1225-1228.

Hannig C, Sorg J, Spitzmuller B, Hannig M, Al-Ahmad A. 2009. Polyphenolic beverages reduce initial bacterial adherence to enamel in situ. J Dent 37:560-566.

Hellström JK, Törrönen AR, Mattila PH. 2009. Proanthocyanidins in common food products of plant origin. J Agric Food Chem 57:7899-7906.

Howell AB. 2007. Bioactive compounds in cranberries and their role in prevention of urinary tract infections. Mol Nutr Food Res 51:732-727.

Johnson-White B, Buquo L, Zeinali M, Ligler FS. 2006. Prevention of nonspecific bacterial cell adhesion in immunoassays by use of cranberry juice. Anal Chem 78:853-7.

Kleinberg I. 2002. A mixed-bacteria ecological approach to understanding the role of the oral bacteria in dental caries causation: an alternative to Streptococcus mutans and the specific-plaque hypothesis. Crit Rev Oral Biol Med 13:108-125.

Kolenbrander PE, Palmer RJ, Jr., Rickard AH, Jakubovics NS, Chalmers NI, Diaz PI. 2006. Bacterial interactions and successions during plaque development. Periodontol 2000 42:47-79.

Kolenbrander PE. 1995. Coaggregations among oral bacteria. Methods Enzymol 253:385397.

Könönen E. 2000. Development of oral bacterial flora in young children. Ann Med 32:107112.

Lätti AK, Riihinen KR, Kainulainen PS. 2008. Analysis of anthocyanin variation in wild populations of bilberry (Vaccinium myrtillus L.) in Finland. J Agric Food Chem 56:190-196.

Lussi A, Jaeggi T. 2008. Erosion - diagnosis and risk factors. Clin Oral Invest 12:5-13. 
377 Matsumoto M, Tsuji M, Okuda J, Sasaki H, Nakano K, Osawa K, Shimura S, Ooshima T.

378

379

380

381

382

383

384

385

386

387

388

389

390

391

392

393

394

395

396

397

398

399 2004. Inhibitory effects of cacao bean husk extract on plaque formation in vitro and in vivo. Eur J Oral Sci 112:249-252.

McIntire FC, Crosby LK, Vatter AE. 1982. Inhibitors of coaggregation between Actinomyces viscosus T14V and Streptococcus sanguis 34: beta-galactosides, related sugars, and anionic amphipathic compounds. Infect Immun 36:371-378.

Määttä-Riihinen KR, Kamal-Eldin A, Törrönen AR. 2004a. Identification and quantification of phenolic compounds in berries of Fragaria and Rubus species (family Rosaceae). J Agric Food Chem 52:6178-6187.

Määttä-Riihinen KR, Kamal-Eldin A, Mattila PH, Gonzalez-Paramas AM, Törrönen AR. 2004b. Distribution and contents of phenolic compounds in eighteen Scandinavian berry species. J Agric Food Chem 52:4477-4486.

Määttä-Riihinen KR, Kähkönen MP, Törrönen AR, Heinonen IM. 2005. Catechins and procyanidins in berries of Vaccinium species and their antioxidant activity. J Agric Food Chem 53:8485-8491.

Määttä K, Kamal-Eldin A, Törrönen R. 2001. Phenolic compounds in berries of black, red, green, and white currants (Ribes sp.). Antioxid Redox Signal 3:981-993.

Ofek I, Hasty DL, Sharon N. 2003. Anti-adhesion therapy of bacterial diseases: prospects and problems. FEMS Immunol Med Microbiol 38:181-191.

Rohr GE, Meier B, Sticher O. 2000. Analysis of procyanidins. In: Atta-ur-Rahman, editor. Studies in Natural Products Chemistry;. New York: Elsevier Science B.V. p 497569.

Rosan B, Lamont RJ. 2000. Dental plaque formation. Microbes Infect 2:1599-1607. 
400 Sbordone L, Bortolaia C. 2003. Oral microbial biofilms and plaque-related diseases: microbial communities and their role in the shift from oral health to disease. Clin Oral Investig 7:181-188.

Steinberg D, Feldman M, Ofek I, Weiss EI. 2005. Cranberry high molecular weight constituents promote Streptococcus sobrinus desorption from artificial biofilm. Int J Antimicrob Agents 25:247-251.

Toivanen M, Huttunen S, Duricová J, Soininen P, Laatikainen R, Loimaranta V, Haataja S, Finne J, Lapinjoki S, Tikkanen-Kaukanen C. 2010. Screening of binding activity of Streptococcus pneumoniae, Streptococcus agalactiae and Streptococcus suis to berries and juices. Phytother Res 24:95-101.

Toivanen M, Ryynänen A, Huttunen S, Duricová J, Riihinen K, Törrönen R, Lapinjoki S, Tikkanen-Kaukanen C. 2009. Binding of Neisseria meningitidis pili to berry polyphenolic fractions. J Agric Food Chem 57:3120-3127.

Viljakainen S, Visti A, Laakso S. 2002. Concentrations of organic acids and soluble sugars in juices from Nordic berries. Acta Agric Scand B 52:101-109.

Weiss EI, Kozlovsky A, Steinberg D, Lev-Dor R, Bar Ness Greenstein R, Feldman M, Sharon N, Ofek I. 2004. A high molecular mass cranberry constituent reduces mutans streptococci level in saliva and inhibits in vitro adhesion to hydroxyapatite. FEMS Microbiol Lett 232:89-92.

Weiss EL, Lev-Dor R, Sharon N, Ofek I. 2002. Inhibitory effect of a high-molecular-weight constituent of cranberry on adhesion of oral bacteria. Crit Rev Food Sci Nutr 42:285-292.

Yamanaka A, Kimizuka R, Kato T, Okuda K. 2004. Inhibitory effects of cranberry juice on attachment of oral streptococci and biofilm formation. Oral Microbiol Immunol 19:150-154. 
425 Yamanaka A, Kouchi T, Kasai K, Kato T, Ishihara K, Okuda K. 2007. Inhibitory effect of 426 cranberry polyphenol on biofilm formation and cysteine proteases of

427 Porphyromonas gingivalis. J Periodontal Res 42:589-592.

\section{FIGURE LEGEND}

429 Figure 1. HPLC-DAD chromatograms at $520 \mathrm{~nm}$ of different molecular size crowberry 430 fractions: $<10 \mathrm{kDa}(\mathrm{FI}), 10-100 \mathrm{kDa}(\mathrm{FII})$, and >100 kDa (FIII). Identity of anthocyanins: 431 (1) delphinidin 3-galactoside, (2) cyanidin 3-galactoside, (3) delphinidin 3-arabinoside, (4) 432 petunidin 3-galactoside, (5) cyanidin 3-arabinoside, (6) peonidin 3-galactoside, and (7) 433 malvidin 3-galactoside. 
434 TABLE 1. Composition of soluble solids (SS) ${ }^{\mathrm{a}}$ in indicated juice fractions.

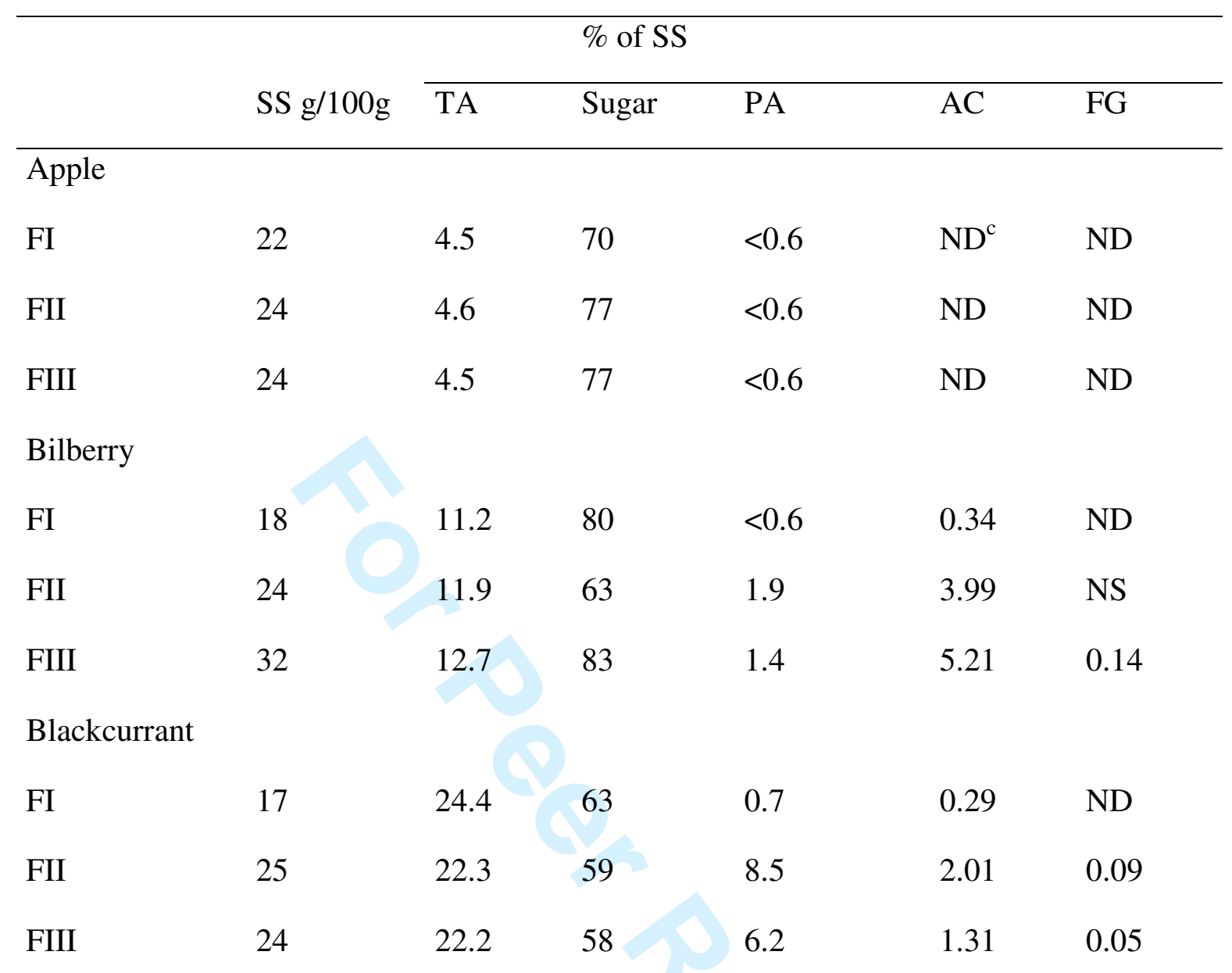

Cloudberry

FI

$18.9 \quad 57$

$<0.6$

ND

ND

FII

19.1

65

$<0.6$

ND

ND

FIII

3

NA

NA

$<0.6$

ND

ND

Crowberry

FI

16

7.4

65

0.7

0.29

ND

FII

22

7.6

55

5.8

$2.80 \quad$ NS

FIII

32

$\begin{array}{ll}7.5 & 48\end{array}$

6.3

$\begin{array}{ll}5.18 & 0.07\end{array}$

Lingonberry

FI

19

$17.4 \quad 52$

1.2

0.09

NS

FII

25

$16.4 \quad 53$

5.8

0.32

NS 


$\begin{array}{lllllll}\text { FIII } & 25 & 15.4 & 63 & 4.7 & 0.21 & \text { NS }\end{array}$

436 a Abbreviations: titratable acids (TA), proanthocyanidins (PA), anthocyanins (AC), flavonol 437 glycosides (FG), not analyzed (NA), not detected (ND), and not significant (NS). buice 438 concentrates were fractionated into three different fractions according to their molecular 439 size, i.e. $<10 \mathrm{kDa}$ fraction (FI), 10-100 kDa fraction (FII), >100 kDa fraction (FIII). ${ }^{\mathrm{c}} \mathrm{No}$ 440 peaks were detected at $520 \mathrm{~nm}$ for AC and at $360 \mathrm{~nm}$ for FG in HPLC-DAD. 
1 TABLE 2. Inhibition (\%) and reversal (\%) of coaggregation between oral bacteria pairs with indicated juice fractions $\mathrm{s}^{\mathrm{a}}$.

\begin{tabular}{|c|c|c|c|c|c|c|c|c|c|}
\hline \multirow[b]{4}{*}{ Fractions } & \multirow[b]{4}{*}{$\mathrm{SS} \mathrm{mg} / \mathrm{g}$} & \multirow{2}{*}{\multicolumn{2}{|c|}{$\begin{array}{l}\text { S. mutans IH } 113728 \& \\
\text { A. naeslundii AHP } 28639\end{array}$}} & \multicolumn{2}{|c|}{ S. mutans IH 113728 \& } & \multicolumn{2}{|c|}{ S. mutans IH $113728 \&$} & \multicolumn{2}{|c|}{ S. mutans IH $113728 \&$} \\
\hline & & & & A. naeslun & AHP 28651 & F. nuclea & AHN 23952 & F. nuclea & AHN 23937 \\
\hline & & \multicolumn{2}{|c|}{ Coaggr. $35( \pm 5) \% \mathrm{n}=22$} & \multicolumn{2}{|c|}{ Coaggr. $34( \pm 6) \% \mathrm{n}=22$} & \multicolumn{2}{|c|}{ Coaggr. $33( \pm 8) \% \mathrm{n}=34$} & \multicolumn{2}{|c|}{ Coaggr. $31( \pm 6) \% \mathrm{n}=34$} \\
\hline & & inhibition $^{b}$ & reversal & inhibition & reversal & inhibition & reversal & inhibition & reversal \\
\hline \multicolumn{10}{|l|}{ Apple } \\
\hline FII & 48 & $<50$ & $<50$ & $<50$ & $<50$ & $<50$ & $<50$ & $<50$ & $<50$ \\
\hline FIII & 48 & $<50$ & $<50$ & $<50$ & $<50$ & $<50$ & $<50$ & $<50$ & $<50$ \\
\hline \multicolumn{10}{|l|}{ Bilberry } \\
\hline FI & $\leq 48$ & $<50$ & $<50$ & $<50$ & $<50$ & $<50$ & $<50$ & $<50$ & $<50$ \\
\hline FIII & 12 & $<50$ & $<50$ & $<50$ & $<50$ & $<50$ & $<50$ & $<50$ & $<50$ \\
\hline FIII & 48 & $77( \pm 27)$ & $<50$ & $<50$ & $79( \pm 24)$ & $<50$ & $80( \pm 23)$ & $<50$ & $<50$ \\
\hline \multicolumn{10}{|c|}{ Black currant } \\
\hline FI & $\leq 48$ & $<50$ & $<50$ & $<50$ & $<50$ & $<50$ & $<50$ & $<50$ & $<50$ \\
\hline FII & 12 & $<50$ & $<50$ & $<50$ & $<50$ & $<50$ & $<50$ & $<50$ & $<50$ \\
\hline FII & 48 & $<50$ & $<50$ & $<50$ & $84( \pm 17)$ & $<50$ & $<50$ & $<50$ & $<50$ \\
\hline
\end{tabular}




$\begin{array}{lllllllll}\text { FIII } & 12 & 71( \pm 13) & <50 & <50 & <50 & <50 & <50 & <50< \\ \text { FIII } & 48 & 79( \pm 21) & 81( \pm 21) & 87( \pm 13) & 90( \pm 6) & <50 & <50 & <50 \quad<50\end{array}$

Cloudberry

$\begin{array}{lllllllll}\text { FI } & 34 & <50 & <50 & <50 & <50 & <50 & <50 & <50 \\ \text { FII } & 40 & <50 & <50 & <50 & <50 & <50 & <50 & <50 \quad<50 \\ \text { FIII } & 33 & <50 & <50 & <50 & <50 & <50 & <50 & <50 \quad<50\end{array}$

Crowberry

\begin{tabular}{|c|c|c|c|c|c|c|c|c|c|}
\hline FI & $\leq 48$ & $<50$ & $<50$ & $<50$ & $<50$ & $<50$ & $<50$ & $<50$ & $<50$ \\
\hline FII & 12 & $<50$ & $<50$ & $<50$ & $<50$ & $<50$ & $<50$ & $<50$ & $<50$ \\
\hline FII & 48 & $83( \pm 21)$ & $93( \pm 8)$ & $91( \pm 12)$ & $90( \pm 12)$ & $85( \pm 17)$ & $98( \pm 1)$ & $71( \pm 28)$ & $95( \pm 8)$ \\
\hline FIII & 12 & $<50$ & $85( \pm 11)$ & $<50$ & $82( \pm 21)$ & $<50$ & $<50$ & $<50$ & $<50$ \\
\hline FIII & 48 & $86( \pm 19)$ & $94( \pm 9)$ & $84( \pm 13)$ & $80( \pm 30)$ & $<50$ & $88( \pm 27)$ & $74( \pm 9)$ & $79( \pm 9)$ \\
\hline \multicolumn{10}{|c|}{ Lingonberry } \\
\hline FI & $\leq 48$ & $<50$ & $<50$ & $<50$ & $<50$ & $<50$ & $<50$ & $<50$ & $<50$ \\
\hline FII & 12 & $<50$ & $<50$ & $<50$ & $<50$ & $<50$ & $<50$ & $<50$ & $<50$ \\
\hline FII & 48 & $81( \pm 22)$ & $100( \pm 0)$ & $94( \pm 8)$ & $97( \pm 7)$ & $80( \pm 14)$ & $88( \pm 14)$ & $83( \pm 12)$ & $99( \pm 1)$ \\
\hline FIII & 12 & $<50$ & $<50$ & $<50$ & $<50$ & $<50$ & $<50$ & $<50$ & $<50$ \\
\hline FIII & 48 & $<50$ & $<50$ & $<50$ & $<50$ & $<50$ & $<50$ & $93( \pm 12)$ & $<50$ \\
\hline
\end{tabular}

$1 \quad{ }^{\mathrm{a}}$ Descriptions of fractions in Table 1. 


\section{Page 27 of 28}

$1{ }^{b}$ Duplicates of bacterial pairs in inhibition and reversal assays were used and each experiment was repeated at least twice. Positive scores over

2 the limit 50\% in reversal and inhibition are shown. Standard deviation is shown in parentheses.

\section{3}


FIGURE 1

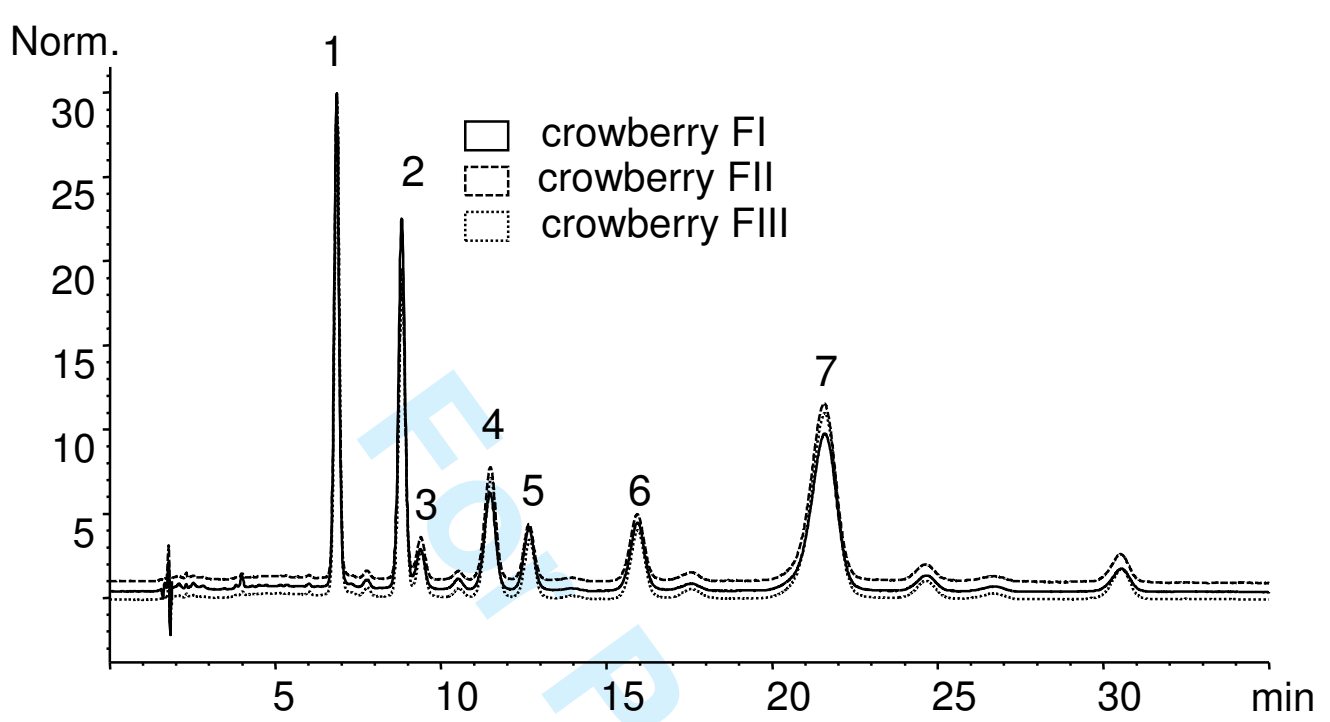

